\title{
Toward an Asian hydroclimate field reconstruction
}

\author{
Takeshi Nakatsuka \\ $4^{\text {th }}$ Asia 2k workshop, Kyoto, Japan, 19-20 March 2015
}

The Asia $2 \mathrm{k}$ working group met at the Research Institute for Humanity and Nature in Kyoto, Japan, to coordinate its phase 2 activities i.e. collecting Asian paleo-records and integrating them into climate, in particular hydroclimate, reconstructions for the past two millennia.

Historical hydroclimate variability, such as severe droughts and floods, has played a key role in people's welfare in Asia. However, creating the hydroclimate field reconstruction (HFR) needed to better understand this natural variability is a significant challenge due to the heterogeneous nature of precipitation over the Asian monsoon region. Data coverage is still scarce for hydroclimate indicators over Asia, and the statistical models still have a challenge integrating the available multi-proxy records with various temporal resolutions. Thus, new data have to be found to fill the spatial gaps, realistic HFR targets set, and the best methods to achieve these discussed; these points were at the center of the discussions at this meeting.

Almost 40 researchers, including $10 \mathrm{grad}$ uate students and postdoctoral fellows, participated in the workshop. Many Asian and non-Asian countries were represented: Japan, China, Russia, India, Pakistan, Nepal, Sri Lanka, Germany, USA, New Zealand, and Switzerland. After an opening remark on the application of Asia 2k's phase 1 results (Cook et al. 2013) in an inter-disciplinary research project (Fig. 1), the first day of the meeting was dedicated to participants' reports on their expertise and research related to Asia2k. On the second day, discussions focused on the goals and timeline of the working group, the status of the data collection, and devising the integration strategies required to achieve the climate field reconstructions.

\section{Although creating spatial hydroclimate} reconstructions is a challenge in the monsoon region, the region has also many advantages, especially thanks to the various types of proxy records available. For example, tree ring chronologies in Asia have great potential to reconstruct past hydroclimate. Many new tree-ring oxygen isotope chronologies were recently published; these can record past changes in regional summer precipitation and relative humidity (e.g. Xu et al. 2013).

In Asia there are also several stalagmite, coral, sediment, and ice core series recording various aspects of the hydroclimate. Together with the tree ring data, all of these proxies can serve as a strong basis for the creation of hydroclimate records. Chinese documentary records on flood and drought covering more than two millennia are also very promising proxies, as well as those from Japan covering the last millennium. Because hydroclimate reconstructions need more densely distributed proxy data than temperature reconstructions and no millennial-long tree-ring chronologies are available from the more populated areas like eastern China, the inclusion of documentary data is crucial.

In a first step, the group has been working on an updated version of the Monsoon Asia Drought Atlas (MADA; Cook et al. 2010). The new MADA will serve as a benchmark for comparison with planned multi-proxy reconstructions, and its tree ring database is the basis for the new data collection. Currently, the group is collecting hydroclimate records and adding them to the database using the same selection criteria and format as used by the $2 \mathrm{k}$ Network for its global temperature database. The goal is to produce a gridded reconstruction of monsoon precipitation using a Bayesian approach. If the data coverage is too sparse for a full spatial reconstruction,

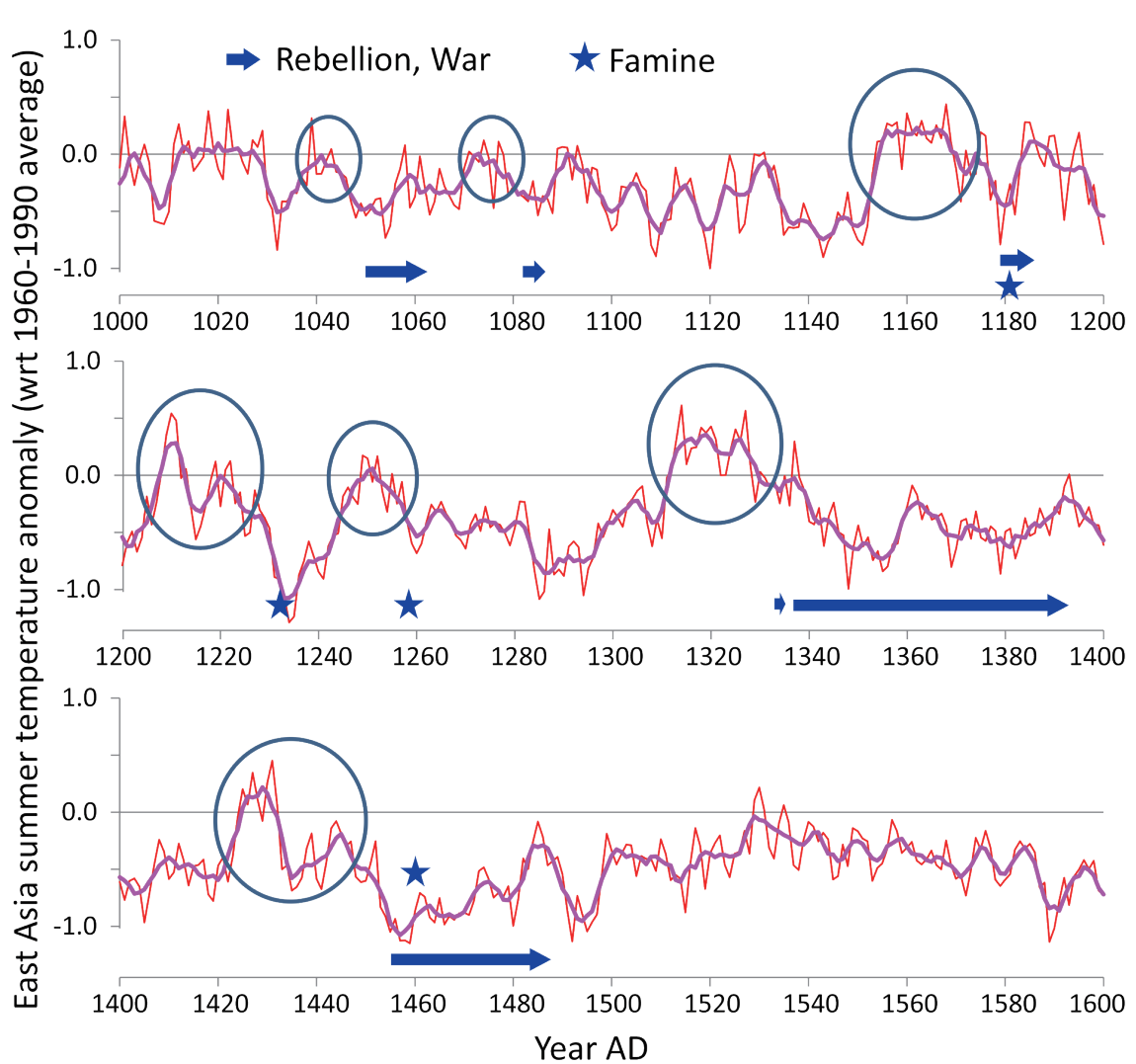

Figure 1: The Asia 2k East Asia summer temperature record (Cook et al. 2013) has enabled the detailed comparison of climate and Japanese history over the last millennium and has stimulated an interdisciplinary research project between paleoclimatologists and historians on societal adaptation to climate change (http:// www.chikyu.ac.jp/rihn_e/project/H-05.html). Major medieval famines and warfare often occurred at times of sudden cooling after multi-decadal warmth. index reconstructions of sub-regions will be targeted. Independent data, such as glacier extents will be considered for validation purposes.

In addition to its main focus on hydroclimate, the group has also produced a first version of a multi-proxy spatial temperature reconstruction (Shi et al. 2015). The final version of the temperature reconstruction will be based on several reconstruction methods and integrate high- and low-resolution records.

\section{AFFILIATIONS}

Research Institute of Humanity and Nature, Kyoto, Japan

CONTACT

Takeshi Nakatsuka: nakatsuka@chikyu.ac.jp

\section{REFERENCES}

Cook ER et al. (2010) Science 328: 486-489 Cook ER et al. (2013) Clim Dyn 41: 2957-2972 Shi F et al. (2015) Clim Change, doi:10.1007/ s10584-015-1413-3

Xu C et al (2013) Palaeogeog, Palaeoclimatol, Palaeoecol 386: 588-598 